\title{
Subclinical Hypothyroidism and Isolated Hypothyroxinemia during Pregnancy and Their Association with Pregnancy Outcome: A 2-Year Study
}

\author{
L. Kalampoki*, G. Tsanadis, T. Stefos \\ Department of Obstetrics \& Gynecology, University Hospital of Ioannina, Ioannina, Greece \\ Email: ${ }^{\star}$ lamprini.kalampoki@gmail.com
}

How to cite this paper: Kalampoki, L., Tsanadis, G. and Stefos, T. (2017) Subclinical Hypothyroidism and Isolated Hypothyroxinemia during Pregnancy and Their Association with Pregnancy Outcome: A 2-Year Study. Open Journal of Obstetrics and Gynecology, 7, 693-701.

https://doi.org/10.4236/ojog.2017.77069

Received: March 23, 2017

Accepted: July 9, 2017

Published: July 12, 2017

Copyright $\odot 2017$ by authors and Scientific Research Publishing Inc. This work is licensed under the Creative Commons Attribution International License (CC BY 4.0).

http://creativecommons.org/licenses/by/4.0/

\begin{abstract}
INTRODUCTION: Overt hypothyroidism in pregnancy is associated with adverse outcomes, but the effects of subclinical hypothyroidism and isolated hypothyroxinemia on pregnancy outcomes are still controversial. Subclinical hypothyroidism might be associated with preterm delivery, low Apgar score, fetal death and miscarriages and isolated hypothyroxinemia with preterm labor, high birth weight and neurocognitive deficits in children. Other studies show no association with any complications at all. In the present study we tried to estimate whether maternal subclinical hypothyroidism and isolated hypothyroxinemia are associated with complications during pregnancy in our population which represents the pregnant population of Western Greece. METHODS: In a total of 469 pregnant women, third trimester serum was assayed for thyroid-stimulating hormone (TSH) and free thyroxine (free T4). Thyroid hypofunction was defined as 1) subclinical hypothyroidism with TSH levels above $3 \mathrm{mIU} / \mathrm{L}$ for the $3^{\text {rd }}$ trimester and normal free T4 and 2) isolated hypothyroxinemia with TSH levels below $3 \mathrm{mIU} / \mathrm{L}$ for the $3^{\text {rd }}$ trimester and free $\mathrm{T} 4$ below the $5^{\text {th }}$ percentile. The results were associated with birth weight, week of labor, history of miscarriages and demographic characteristics. Patients with thyroid hypofunction were compared with euthyroid patients (TSH and free T4 between normal limits). The results were analyzed with one-way ANOVA and $\chi^{2}$ test. RESULTS: Subclinical hypothyroidism was documented in $10.9 \%$ and isolated hypothyroxinemia in $21.7 \%$ of pregnant women. Subclinical hypothyroidism was not associated with birth weight, week of labor, or history of miscarriages. On the contrary, hypothyroxinemia was associated with high birth weight $(\mathrm{P}<0.05)$. CONCLUSION: In our study, we did not find a link between subclinical hypothyroidism and adverse pregnancy outcomes. Similarly, hypothyroxinemia was not associated with pregnancy complications. However, it was associated with higher birth
\end{abstract}


weight. Our studies contribute to our understanding, whether or not subclinical hypothyroidism and isolated hypothyroxinemia are associated with pregnancy adverse outcomes and whether treatment and test for hypothyroidism should become routine during pregnancy.

\section{Keywords}

Subclinical Hypothyroidism, Isolated Hypothyroxinemia, Pregnancy

\section{Introduction}

Normal pregnancy entails substantial changes in maternal thyroid function. Inadequate adaptation to these changes in thyroid physiology results in thyroid dysfunction [1] [2]. Some of these alterations in thyroid function occur due to increased thyroid hormone-binding globulin (TBG), iodine clearance in the kidneys, and thyrotrophic effect of human chorionic gonadotropin (HCG) [3] [4]. The prevalence of overt hypothyroidism is $1 \%-1.5 \%$ [5], of subclinical hypothyroidism $1.5 \%-5 \%$ [6] and of isolated hypothyroxinemia, $2.5 \%$ [7]. The 2011 American Thyroid Association guideline for diagnosis of thyroid disease in pregnancy determined the normal limits of TSH as $0.1-2.5 \mathrm{mlU} / \mathrm{L}$ in the first, $0.2-3 \mathrm{mlU} / \mathrm{L}$ in the second and $0.3-3.0 \mathrm{mlU} / \mathrm{L}$ in the third trimester [8]. Overt hypothyroidism is defined as TSH levels above these limits and fT4 below the 5th percentile. Subclinical hypothyroidism is defined as TSH above these limits and fT4 between the 5th and 95th percentile and isolated hypothyroxinemia as TSH below the above limits and fT 4 below the 5 th percentile.

Although it is established that overt hypothyroidism in pregnancy is associated with many of adverse outcomes, the effects of subclinical hypothyroidism and isolated hypothyroxinemia on pregnancy outcomes are still controversial [9]-[18].

Subclinical hypothyroidism might be associated with preterm delivery, low Apgar score, fetal death and miscarriages [19] [20] [21] [22]. According to other studies, it is not associated with any complications. Equally, isolated hypothyroxinemia is associated with preterm labor, high birth weight and neurocognitive deficits in children. In other studies there was no association with complications [23] [24]. According to other studies, subclinical hypothyroidism affects $0.4 \%-1 \%$ of pregnancies and isolated hypothyroxinemia about $2 \%$, in iodinesufficient regions and $25 \%-30 \%$ in iodine deficient regions [24]. The 2011 guidelines for the management of thyroid dysfunction do not recommend universal screening of healthy women for thyroid dysfunction before pregnancy [8]. We carried out the present study in order to know whether the subclinical hypothyroidism or isolated hypothyroxinemia are associated with adverse pregnancy complications in our pregnant population of Western Greece.

\section{Materials and Methods}

Maternal thyroid hypofunction was defined as 1) subclinical hypothyroidism 
when TSH was more than $3 \mathrm{mIU} / \mathrm{L}$ for the $3^{\text {rd }}$ trimester and free T4 between the $5^{\text {th }}$ and $95^{\text {th }}$ percentiles or 2 ) isolated hypothyroxinemia when TSH was less than $3 \mathrm{mIU} / \mathrm{L}$ for the $3^{\text {rd }}$ trimester and free T4 less than the $5^{\text {th }}$ percentile. Overt hypothyroidism is defined as an elevated TSH $\left(>2.5 \mathrm{mIU} / \mathrm{L}\right.$ for the $1^{\text {st }}$ trimester or $3 \mathrm{mIU} / \mathrm{L}$ for the $3^{\text {rd }}$ trimester) in conjunction with a decreased $\mathrm{FT}_{4}$ concentration. Women with TSH levels of $10.0 \mathrm{mIU} / \mathrm{L}$ or above, irrespective of their $\mathrm{FT}_{4}$ levels, are also considered to have overt hypothyroidism.

This is a retrospective study carried out at O\&G clinic of the University Hospital, Ioannina. We went through the medical records of 2200 pregnant women followed up in our department throughout the years 2014 and 2015. We searched for evidence of thyroid function testing for these women, as in our hospital thyroid function control is not routinely tested during pregnancy. We identified 469 (21.3\%) healthy singleton pregnant women whose third trimester thyroid function was tested during these 2 years. The included women were assigned to 3 different groups: Group $1(n=273)$ were euthyroid, Group $2(n=51)$ had subclinical hypothyroidism and Group $3(n=102)$ had isolated hypothyroxinemia. The rest $(n=43$ ) were excluded from the study as they had Overt Hypothyroidism and other thyroid function issues. We also excluded those with chronic conditions, such as diabetes mellitus, hypertension or other autoimmune diseases. The Socio Demographic characteristics of the study population have been included in Table 1.

Each one of the pregnant women, apart from the thyroid function, was also checked for obstetric outcomes and specifically the week of labor, birth weight

Table 1. Socio demographic characteristics of participants.

\begin{tabular}{|c|c|c|c|}
\hline & Total & Group 1 & Group 2 \\
\hline & & normal fT4 \& high TSH & low fT4 \& normal TSH \\
\hline $\mathrm{n}$ & 469 & 51 & 102 \\
\hline min Age & 17 & 22 & 17 \\
\hline $\max$ Age & 44 & 41 & 44 \\
\hline mean Age & $31.81(17-44)$ & $31.35(22-41)$ & $32.5(17-44)$ \\
\hline mean GA & $38(25.6-41.3)$ & $37.9(28.1-40.4)$ & $38.3(30-41.1)$ \\
\hline mean BW & $3105(690-4880)$ & $3102(690-4110)$ & $3283(2230-4880)$ \\
\hline mean miscarriages & $0.31(0-4)$ & $0.24(0-3)$ & $0.37(0-3)$ \\
\hline mean previous CS & $0.37(0-3)$ & $0.25(0-1)$ & $0.44(0-2)$ \\
\hline male & $51.40 \%$ & $47.10 \%$ & $54.90 \%$ \\
\hline CS & $65.20 \%$ & 54.9 & $66.70 \%$ \\
\hline Diabetic & $6.80 \%$ & $9.80 \%$ & $4.90 \%$ \\
\hline Preeclampsia & $3.20 \%$ & $5.90 \%$ & $1 \%$ \\
\hline Current Smoker & $7.30 \%$ & $2 \%$ & $5.90 \%$ \\
\hline Previous Smoker & $8.10 \%$ & $9.80 \%$ & $7.80 \%$ \\
\hline Non-smoker & $84.20 \%$ & $86.30 \%$ & $86.30 \%$ \\
\hline Rh neg & $6.40 \%$ & $3.90 \%$ & $7.80 \%$ \\
\hline
\end{tabular}


and the history of miscarriages (fetal loss before 24 weeks of gestation). Potential confounding factors including maternal age, parity, smoking, and history of medical problems, gender of the embryo, Rh profile and birth with cesarean section for each one of the pregnant women were also examined and were correlated with thyroid function. In order to investigate a possible correlation between thyroid function and cesarean section labor, we considered only women who had their first CS during this study period.

We used one-way ANOVA to compare the means of numerical data between the 3 groups and chi-square test to assess the relationship between maternal thyroid function and obstetric outcomes. Further regression modeling identified the statistically significant obstetric outcomes in the thyroid hypofunction group.

\section{Results}

A total of 469 singleton pregnant women enrolled in the study. We tested their thyroid function during the third trimester and a percentage of 5.5\% (26 of 469) were found to have overt hypothyroidism, $10.9 \%$ were found to have subclinical hypothyroidism (51 of 469), 21.7\% isolated hypothyroxinemia (102 of 469) and $58.2 \%$ (273 of 469) were found to be euthyroid (Chart 1) and 9.1\% (43 of 469) did not fit to any category. Women with overt hypothyroidism or other chronic disease such as diabetes mellitus, hypertension or other autoimmune disease were excluded from the study.

The Socio Demographic Characteristics of the study population are given in Table 1 . The mean age of the study population was 31.8 years and the mean gestational age (GA) 38 weeks. In this study we also checked the mean birth

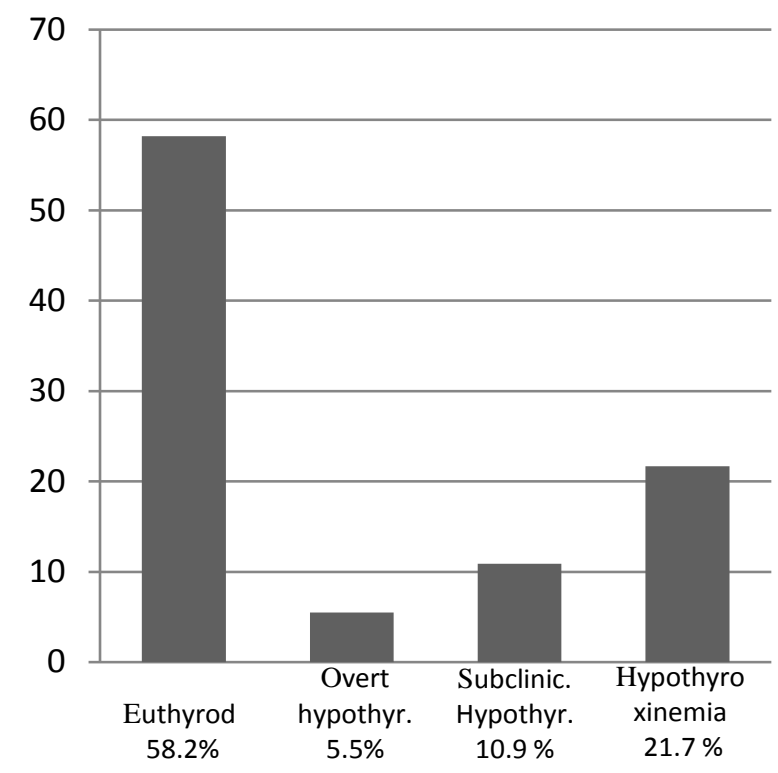

Chart 1. Prevalence of overt hypothyroidism, subclinical hypothyroidism and isolated hypothyroxinemia in the total of 469 pregnant women who were tested at the University Hospital of Ioannina, during the years 2014-2015. 
weight (BW), mean number of miscarriages and the mean number of previous cesarean sections (CS). In addition, we also checked the prevalence of the male gender of the embryo, of caesarian section, the percentage of other diseases such as diabetes mellitus and preeclampsia, the percentage of smokers and Rh negative blood profile. All the above characteristics were examined for the total of the participants and for those with subclinical hypothyroidism and isolated hypothyroxinemia separately. Group 1 in Table 1 corresponds to subclinical hypothyroid participants and Group 2 to those with isolated hypothyroxinemia.

Subclinical hypothyroidism and hypothyroxinemia were associated with Gestational age of delivery (GA), birth weight (BW), and history of miscarriage and patients were compared with euthyroid ones (Table 2). Analysis of the results shows that subclinical hypothyroidism does not affect birth weight or week of labor and does not have any correlation with history of miscarriages (Table 2) and analysis of the results for isolated hypothyroxinemia, show that hypothyroxinemia does not affect the week of labor and is not associated with history of miscarriages. To the contrary, the analysis shows that hypothyroxinemia is associated with higher infants' birth weight than those of euthyroid women $(\mathrm{P}<$ 0.05) (Table 2).

Mean maternal age, parity, smoking, gender of embryo; Rh profile and cesarean section for first time were similar in the three studied groups (Table 3).

\section{Discussion}

Thyroid disease is the second most common endocrine disorder complicating

Table 2. Comparison of the obstetric outcomes of patients with thyroid hypofunction compared with euthyroid patients.

\begin{tabular}{ccccc}
\hline & $\begin{array}{c}\text { Subclinical } \\
\text { Hypothyroid } \\
(\mathrm{n}=51)\end{array}$ & $\begin{array}{c}\text { Isolated Hypothyroxinemia } \\
(\mathrm{n}=102)\end{array}$ & $\begin{array}{c}\text { Euthyroid } \\
(\mathrm{n}=273)\end{array}$ & $\mathrm{p}$ \\
\hline GA & $37.925 \pm 2.36$ & $38.302 \pm 1.46$ & $37.77 \pm 2.07$ & 0.075 \\
BW & $3101 \pm 650$ & $3282 \pm 425$ & $3035 \pm 517$ & $<0.05$ \\
Prior Miscarriage & $17.60 \%$ & $31.40 \%$ & $24.20 \%$ & 0.112 \\
\hline
\end{tabular}

Table 3. Comparison of the demographic characteristics of patients with thyroid hypofunction compared with euthyroid patients.

\begin{tabular}{ccccc}
\hline & $\begin{array}{c}\text { Subclinical } \\
\text { Hypothyroid } \\
(\mathrm{n}=51)\end{array}$ & $\begin{array}{c}\text { Isolated Hypothyroxinemia } \\
(\mathrm{n}=102)\end{array}$ & $\begin{array}{c}\text { Euthyroid } \\
(\mathrm{n}=273)\end{array}$ & $\mathrm{p}$ \\
\hline Age & $31.35 \pm 4.53$ & $32.5 \pm 4.99$ & $31.64 \pm 4.85$ & 0.24 \\
Prior Pregnancy & $42.90 \%$ & $54.90 \%$ & $52.60 \%$ & 0.364 \\
Smoking & $2 \%$ & $5.90 \%$ & $9.50 \%$ & 0.386 \\
Rh negative & $3.90 \%$ & $7.80 \%$ & $5.80 \%$ & 0.607 \\
Male birth & $47.10 \%$ & $54.90 \%$ & $50.40 \%$ & 0.612 \\
CS & $41.00 \%$ & $44.30 \%$ & $54.30 \%$ & 0.182 \\
\hline
\end{tabular}


pregnancy. Attention to thyroid dysfunction during pregnancy has certainly increased in the past decade, particularly in the area of subclinical thyroid dysfunction.

Overt hypothyroidism affects pregnancy and neonatal outcomes in many ways. Many published studies have shown that overt hypothyroidism is associated with preterm labor, low birth weight, miscarriages, intrauterine embryo death and neurodevelopmental complications for the infant [25] [26] [27] [28] [29].

In our study we found that $5.5 \%$ of the tested pregnant women were known hypothyroid and they had started treatment from the first trimester. The probable explanation for this high prevalence may be the deficiency of Iodine in the diet of the pregnant population of Ioannina.

On the other hand the effects of maternal subclinical hypothyroidism and isolated hypothyroxinemia on pregnancy and neonatal outcomes are not definitely confirmed and conflicted results exist among the published studies [19] [22] [24] [25] [26] [27].

In one study of women screened before midpregnancy, women with subclinical hypothyroidism had higher incidences of preterm birth, placental abruption, and admission of infants to the intensive care nursery when compared with control women [30]. Conversely, in another study of First- and Second-Trimester Evaluation of Risk (FASTER) Trial participants, Cleary-Goldman et al. [22] did not find a link with adverse obstetrical outcomes, such as miscarriage, gestational hypertension, preeclampsia, gestational diabetes, placenta previa, placenta abruption, preterm labor, premature rupture of membranes, low or high birth weight and perinatal mortality.

In a study of 233 pregnant women with isolated hypothyroxinemia, Casey et al. [31] reported that there were no increased adverse perinatal outcomes associated with the condition. Conversely, Cleary-Goldman et al. [22] reported a 2fold incidence of fetal macrosomia in these women. In another smaller study of 89 women with maternal hypothyroxinemia, there was no evidence of an increased risk for fetal growth restriction or preterm birth [32].

Because there are still ongoing studies trying to clarify whether or not maternal subclinical hypothyroidism and isolated hypothyroxinemia on pregnancy are associated with adverse outcomes, we decided to carry out the present study to contribute to this still unanswered question. In addition to this, this study is a unique study in the region of Western Greece.

In our study among adverse outcomes, we decided to investigate neonatal birth weight, week of labor and association with miscarriage. We also tried to find if there was an association between thyroid function and maternal age, parity, smoking, Rh, fetus gender and mode of delivery.

Our results indicate that subclinical hypothyroidism was not associated with neonatal birth weight, week of labor or history of miscarriage, a finding which agrees with that of Clearly-Goldman et al. [22]. There was also no association with the other demographic characteristics that were tested. 
Unlike subclinical hypothyroidism, isolated hypothyroxinemia in our study was associated with higher birth weight, but not with history of miscarriage or with the week of labor. Clearly-Goldman et al showed also that women with isolated hypothyroxinemia were not at increased risk for the majority of pregnancy complications [22]. However, hypothyroxinemia was associated with birth weight greater than $4000 \mathrm{~g}$, a finding similar to ours, namely that women with hypothyroxinemia give birth to heavier babies than euthyroid ones.

Women with diabetes mellitus, hypertension and autoimmune diseases were excluded from our study, as all those conditions are considered confounding factors.

In summary, we did not find a link between subclinical hypothyroidism and adverse pregnancy outcomes in our population. Similarly, hypothyroxinemia was not associated with the majority of pregnancy complications. However, hypothyroxinemia was associated with higher birth weight. This study can be a useful tool in neonatologist hands, to investigate how maternal subclinical hypothyroidism and isolated hypothyroxinemia, might affect neonate and child development and behavior.

We note the following limitations of this study. The study was conducted retrospectively including results from a single, but large, centre where pregnancies from the wider West area of Greece are treated. Also we have not accounted the BMI of women in this study. Our findings combined with results from other studies will help to clarify the still unanswered question of whether maternal subclinical hypothyroidism and isolated hypothyroxinemia should be treated and whether a test for hypothyroidism should become routine during pregnancy.

\section{Disclosure}

We certify that no actual or potential conflicts of interest in relation to this article exist.

\section{References}

[1] Mannisto, T., Vaarasmaki, M., Pouta, A., Hartikainen, A.L., Ruokonen, A., Surcel, H.M, et al. (2010) Thyroid Dysfunction and Autoantibodies during Pregnancy as Predictive Factors of Pregnancy Complications and Maternal Morbidity in Later Life. Journal of Clinical Endocrinology \& Metabolism, 95, 1084-1094. https://doi.org/10.1210/jc.2009-1904

[2] Glinoer, D. (1997) The Regulation of Thyroid Function in Pregnancy: Pathways of Endocrine Adaptation from Physiology to Pathology. Endocrine Reviews, 18, 404433. https://doi.org/10.1210/edrv.18.3.0300

[3] Moleti, M., Trimarchi, F. and Vermiglio, F. (2014) Thyroid Physiology in Pregnancy. Endocrine Practice, 20, 589-596. https://doi.org/10.4158/EP13341.RA

[4] Skjoldebrand, L., Brundin, J., Carlstrom, A. and Pettersson, T. (1982) Thyroid Associated Components in Serum during Normal Pregnancy. Acta Endocrinology (Copenh), 100, 504-511.

[5] Vanderpump, M.P. and Tunbridge, W.M. (2002) Epidemiology and Prevention of 
Clinical and Subclinical Hypothyroidism. Thyroid, 12, 839-847. https://doi.org/10.1089/105072502761016458

[6] Vanderpump, M.P.J. (2011) The Epidemiology of Thyroid Disease. British Medical Bulletin, 99, 39-51. https://doi.org/10.1093/bmb/ldr030

[7] Krassas, G.E., et al. (2010) Thyroid Function and Human Reproductive Health. Endocrine Reviews, 31, 702-755. https://doi.org/10.1210/er.2009-0041

[8] Stagnaro-Green, A., Abalovich, M., Alexander, E., Azizi, F., Mestman, J., Negro, R., Nixon, A., Pearce, E., Soldin, O., Sullivan, S. and Wiersinga, W. (2011) Guidelines of the American Thyroid Association for the Diagnosis and Management of Thyroid Disease during Pregnancy and Postpartum. Thyroid, 21, 1081-1125. https://doi.org/10.1089/thy.2011.0087

[9] Karakosta, P., Alegakis, D., Georgiou, V., Roumeliotaki, T., Fthenou, E., Vassilaki, M., et al. (2012) Thyroid Dysfunction and Autoantibodies in Early Pregnancy Are Associated with Increased Risk of Gestational Diabetes and Adverse Birth Outcomes. Journal of Clinical Endocrinology \& Metabolism, 97, 4464-4472. https://doi.org/10.1210/jc.2012-2540

[10] Su, P.Y., Huang, K., Hao, J.H., Xu, Y.Q., Yan, S.Q., Li, T., et al. (2011) Maternal Thyroid Function in the First Twenty Weeks of Pregnancy and Subsequent Fetal and Infant Development: A Prospective Population-Based Cohort Study in China. Journal of Clinical Endocrinology \& Metabolism, 96, 3234-3241. https://doi.org/10.1210/jc.2011-0274

[11] Stagnaro-Green, A. (2009) Maternal Thyroid Disease and Preterm Delivery. Journal of Clinical Endocrinology \& Metabolism, 94, 21-25. https://doi.org/10.1210/jc.2008-1288

[12] Mannisto, T., Mendola, P., Reddy, U. and Laughon, S.K. (2013) Neonatal Outcomes and Birth Weight in Pregnancies Complicated by Maternal Thyroid Disease. American Journal of Epidemiology, 178, 731-740. https://doi.org/10.1093/aje/kwt031

[13] Sahu, M.T., Das, V., Mittal, S., Agarwal, A. and Sahu, M. (2010) Overt and Subclinical Thyroid Dysfunction among Indian Pregnant Women and Its Effect on Maternal and Fetal Outcome. Archives of Gynecology and Obstetrics, 281, 215-220. https://doi.org/10.1007/s00404-009-1105-1

[14] Poppe, K. and Glinoer, D. (2003) Thyroid Autoimmunity and Hypothyroidism before and during Pregnancy. Human Reproduction Update, 9, 149-161. https://doi.org/10.1093/humupd/dmg012

[15] Blazer, S., Moreh-Waterman, Y., Miller-Lotan, R., Tamir, A. and Hochberg, Z. (2003) Maternal Hypothyroidism May Affect Fetal Growth and Neonatal Thyroid Function. Obstetrics \& Gynecology, 102, 232.

[16] Min, H., Dong, J., Wang, Y., Wang, Y., Teng, W., Xi, Q. and Chen, J. (2016) Maternal Hypothyroxinemia-Induced Neurodevelopmental Impairments in the Progeny. Molecular Neurobiology, 53, 1613-1624 https://doi.org/10.1007/s12035-015-9101-x

[17] Korevaar, T., Muetzel, R., Medici, M., Chaker, L., Jaddoe, V.W., de Rijke, Y.B., Steegers, E.A., Visser, T.J., White, T., Tiemeier, H. and Peeters, R.P. (2016) Association of Maternal Thyroid Function during Early Pregnancy with Offspring IQ and Brain Morphology in Childhood a Population-Based Prospective Cohort Study. The Lancet Diabetes \& Endocrinology, 4, 35-43. https://doi.org/10.1016/S2213-8587(15)00327-7

[18] Taylor, P.N., Okosieme, O.E. Premawardhana, L. and Lazarus, J.H. (2015) Should All Women Be Screened for Thyroid Dysfunction in Pregnancy? Womens Health, 11, 295-307. https://doi.org/10.2217/whe.15.7 
[19] Usadi, R.S. and Meriam, K.S. (2016) Subclinical Hypothyroidism Impact on Fertility Obstetric and Neonatal Outcomes. Seminars in Reproductive Medicine, 34, 337342. https://doi.org/10.1055/s-0036-1593486

[20] Negro, R. (2011) Thyroid Disease in Pregnancy. Endocrinology and Metabolism, 25, 927-943. https://doi.org/10.1016/j.beem.2011.07.010

[21] Idris, I., Shrinivasan, R., Simm, A. and Page, R.C. (2005) Maternal Hypothyroidism in Early and Late Gestation; Effects on Neonatal and Obstetric Outcome. Clinical Endocrinology, 63, 560-565. https://doi.org/10.1111/j.1365-2265.2005.02382.x

[22] Cleary-Goldman, J., Malone, F.D., Lambert-Messerlian, G., Sullivan, L., Canick, J., Porter, T.F., Luthy, D., Gross, S., Bianchi, D.W. and D'Alton, M.E. (2008) Maternal Thyroid Hypofunction and Pregnancy Outcome. Obstetrics \& Gynecology, 112, 85-92. https://doi.org/10.1097/AOG.0b013e3181788dd7

[23] Pop, V.J., Kuijpens, J.L., van Baar, A.L., et al. (1999) Low Maternal Free Thyroxine Concentrations during Early Pregnancy Are Associated with Impaired Psychomotor Development in Infancy. Clinical Endocrinology $(O x f)$, 50, 149-155. https://doi.org/10.1046/j.1365-2265.1999.00639.x

[24] Moleti, M., Trimarchi, F. and Vermiglio, F. (2011) Doubts and Concerns about Isolated Maternal Hypothyroxinemia. Journal of Thyroid Research, 2011, Article ID: No. $463029,7$.

[25] Abalovich, M., Guiterrez, S., Alcaraz, G., Maccallini, G., Garcia, A. and Levalle, O. (2002) Overt and Subclinical Hypothyroidism Complicating Pregnancy. Thyroid, 12, 63-68. https://doi.org/10.1089/105072502753451986

[26] Allan, W.C., Haddow, J.E., Palomaki, G.E., Williams, J.R., Mitchell, M.L., Hermos, R.J., Faix, J.D. and Klein, R.Z. (2000) Maternal Thyroid Deficiency and Pregnancy Complications: Implications for Population Screening. Journal of Medical Screening, 7, 127-130. https://doi.org/10.1136/jms.7.3.127

[27] Casey, B.M. (2011) Subclinical Thyroid Dysfunction during Pregnancy. Clinical Obstetrics and Gynecology, 54, 493-498. https://doi.org/10.1097/GRF.0b013e31822e27e3

[28] Benhadi, N., Wiersinga, W.M., Reitsma, J.B., Vrijkotte, T.G. and Bonsel, G.J. (2009) Higher Maternal TSH Levels in Pregnancy Are Associated with Increased Risk for Miscarriage, Fetal or Neonatal Death. European Journal of Endocrinology, 160, 985-991. https://doi.org/10.1530/EJE-08-0953

[29] Mannisto, T., Vaarasmaki, M., Pouta, A., Hartikainen, A.L., Ruokonen, A., Surcel, H.M., Bloigu, A., Järvelin, M.R. and Suvanto-Luukkonen, E. (2009) Perinatal Outcome of Children Born to Mothers with Thyroid Dysfunction or Antibodies: A Prospective Population-Based Cohort Study. Journal of Clinical Endocrinology \& Metabolism, 94, 772-779. https://doi.org/10.1210/jc.2008-1520

[30] Casey, B.M., Dashe, J.S., Wells, C.E., et al. (2005) Subclinical Hypothyroidism and Pregnancy Outcomes. Obstetrics \& Gynecology, 105, 239-245. https://doi.org/10.1097/01.AOG.0000152345.99421.22

[31] Casey, B.M., Dashe, J.S., Spong, C.Y., et al. (2007) Perinatal Significance of Isolated Maternal Hypothyroxinemia Identified in the First Half of Pregnancy. Obstetrics \& Gynecology, 109, 1129. https://doi.org/10.1097/01.AOG.0000262054.03531.24

[32] Hamm, M.P., Cherry, N.M., Martin, J.W., et al. 2009) The Impact of Isolated Maternal Hypothyroxinemia on Perinatal Morbidity. Journal of Obstetrics and Gynaecology Canada, 31, 1015-1021. 
Submit or recommend next manuscript to SCIRP and we will provide best service for you:

Accepting pre-submission inquiries through Email, Facebook, LinkedIn, Twitter, etc. A wide selection of journals (inclusive of 9 subjects, more than 200 journals)

Providing 24-hour high-quality service

User-friendly online submission system

Fair and swift peer-review system

Efficient typesetting and proofreading procedure

Display of the result of downloads and visits, as well as the number of cited articles Maximum dissemination of your research work

Submit your manuscript at: http://papersubmission.scirp.org/

Or contact ojog@scirp.org 